\title{
Gigantic Abdominal Pseudocyst: An Unusual Evolution of the Ventriculoperitoneal Shunt
}

\author{
Alícia de Oliveira Mendes', Fernanda Aquino Freres Silva1, Luiza Kohmann Salvoni1, \\ Willy Marcus França1,2* \\ ${ }^{1}$ Medical Science and Health Faculty, PUC/SP (FCMS, PUC/SP), Campus Sorocaba, Sorocaba, Brazil \\ ${ }^{2}$ Laboratory of Surgery Technique and Experimental Surgery of FCMS, PUC/SP, Campus Sorocaba, Sorocaba, Brazil \\ Email: *willy@drwilly.com.br
}

How to cite this paper: Mendes, A. de O., Silva, F.A.F., Salvoni, L.K. and França, W.M. (2021) Gigantic Abdominal Pseudocyst: An Unusual Evolution of the Ventriculo- peritoneal Shunt. Open Journal of Modern Neurosurgery, 11, 252-257.

https://doi.org/10.4236/ojmn.2021.114029

Received: September 15, 2021

Accepted: October 12, 2021

Published: October 15, 2021

Copyright $\odot 2021$ by author(s) and Scientific Research Publishing Inc. This work is licensed under the Creative Commons Attribution International License (CC BY 4.0).

http://creativecommons.org/licenses/by/4.0/

\begin{abstract}
Background: The ventriculoperitoneal (VPS) shunt is the most common procedure in the treatment of hydrocephalus in children. Abdominal cerebrospinal fluid pseudocysts are a rare complication of the ventriculoperitoneal shunt with an incidence ranging from less than $1 \%$ to $10 \%$ and are more prevalent in children. The malfunction of the ventriculoperitoneal shunt can cause headaches, nausea, vomiting, altered level of consciousness and abdominal pain due to the accumulation of cerebrospinal fluid. There is no consensus on which type of treatment is better in this case, but there are several available methods. Aim: To report an unusual case of a giant abdominal cerebrospinal fluid pseudocyst as a complication of the VPS. Case Presentation: Female $1 \mathrm{y} / 3$ months old patient, less than $7 \mathrm{~kg}$, that has been diagnosed with hydrocephalus prenatally, confirmed postnatally associated with an esophageal atresia and distal tracheoesophageal fistula (AE/FTE, Gross III), was admitted to our service with progressive abdominal distention without obstructive intestinal signs or peritoneal inflammatory signs. The CT scan of the abdomen showed a large liquid collection (estimated volume of $600 \mathrm{ml}$ ), centered on the umbilical region, diagnosed as a giant abdominal cerebrospinal fluid (CSF) pseudocyst from the VPS. All of data and information were obtained from her medical records at the infirmary of the Conjunto Hospitalar de Sorocaba (CHS), São Paulo. Conclusion: Abdominal CSF as a cause of these giant pseudocysts should be considered as a diagnostic hypothesis for cases of large abdominal distensions without intestinal involvement in patients with a VPS. This research did not receive any specific grant from funding agencies in the public, commercial, or not-for-profit sectors.
\end{abstract}

\section{Keywords}

Abdominal Cerebrospinal Fluid Pseudocysts, Ventriculoperitoneal Shunt 


\section{Introduction}

Hydrocephalus is characterized by the accumulation of cerebrospinal fluid (CSF) in the cerebral ventricles in children. It is usually treated using ventricle shunts to the peritoneum, atrium, pleura or even external [1]. The use of ventriculoperitoneal shunt (VPS) is the most common neurosurgical procedure in the treatment of hydrocephalus in children [1], in order to decrease intracranial pressure [2], avoiding huge head volume. VPS can avoid several types of complications including infections, abscesses, intestinal perforation and abdominal CSF pseudocysts [2] [3] [4] [5] [6].

Despite abdominal pseudocyst was first reported by Harsch in 1954 [2], during the use of shunts for the peritoneal cavity [7], one year later, Jackson and Snodgrass mentioned similar complication as well [8] [9].

CSF pseudocyst has an uncertain etiology but comes from infections in the catheter or due to CSF malabsorption by the peritoneum [2] [5] [10] [11]. The time between placement of the VPS and cyst formation varies from 3 weeks to 5 years [2] and can be mobile or attached to abdominal organs [3]. Larger cysts described in this report tend to be sterile but smaller ones tend to be infected [12] [13]. It is usually preceded by recent inflammatory or infectious state, or recent surgery, frequently in early childhood and adolescence [11] [12] [13].

The diagnosis of abdominal CSF pseudocysts is made more commonly by ultrasound or abdominal CT [3] [4] [5] [10]. The diagnosis must be quick in order to avoid complications [2], which can be: abdominal obstruction, infections, insufficient or excessive drainage of CSF and consequent collapse of the ventricles, or intracranial hypertension [5] [6] [11]. The patient in the present clinical case did not present any of them.

Treatment depends on the clinical condition presented, but percutaneous puncture can be performed with or without repositioning the catheter in an alternative location [5] [10] [13].

The clinical case below aims to report the possibility of the formation of giant peritoneal CSF pseudocysts in the presence of a ventriculoperitoneal shunt, and to differentiate them from clinical conditions relating to bowel obstruction in children with other digestive tract malformations.

\section{Case Report}

One year and 3 months old female patient, weighing no more than $7 \mathrm{~kg}$, that has been diagnosed with hydrocephalus prenatally, confirmed postnatally associated with an esophageal atresia and distal tracheoesophageal fistula (Gross III). The diagnosis of hydrocephalus was confirmed at birth, and she evolved with an increasing cranial circumference for four days, when a ventriculoperitoneal shunt (VPS) was placed on the left side of her head. The following day the child underwent surgery for the esophageal atresia and distal tracheoesophageal fistula, with an esophagoplasty and suture of tracheoesophageal fistula. At twenty-eight 
days the VPS was obstructed and the system was switched to the right side.

When the child was $1 \mathrm{y} / 3$ months old, she was referred to our service with a history of progressive abdominal distension, without obstructive intestinal signs or peritoneal inflammatory signs. Her food and water intake were normal, but there was an increase in her temperature during this period (above $38^{\circ} \mathrm{C}$ ) and weight gain (500 g in 1 week). The ultrasound showed an image compatible with huge abdominal volume, and that is why she was transferred to the Neurosurgery and Pediatric Surgery service at the Sorocaba Regional Center Hospital, São Paulo, Brazil.

She was immediately admitted to the service and a CT scan of the abdomen was requested, which showed a large liquid collection with an estimated volume of $600 \mathrm{ml}$ (Figure 1). It was then diagnosed as a giant abdominal CSF pseudocyst.

The child underwent abdominal puncture three times and the neurosurgery service decided to exchange the VPS for an external ventricular shunt as an emergency procedure, removing $600 \mathrm{ml}$ of CSF this time. After the last puncture and the removal of the ventriculoperitoneal shunt, the pseudocyst was drained again, and the abdomen gradually reduced.

The patient spent 12 days in the Intensive Care Unit and 18 days at the nursery. She continued without complications and was discharged after 1 month of hospitalization.

\section{Discussion}

Hydrocephalus generally requires a peritoneal shunt, whose function is to drain

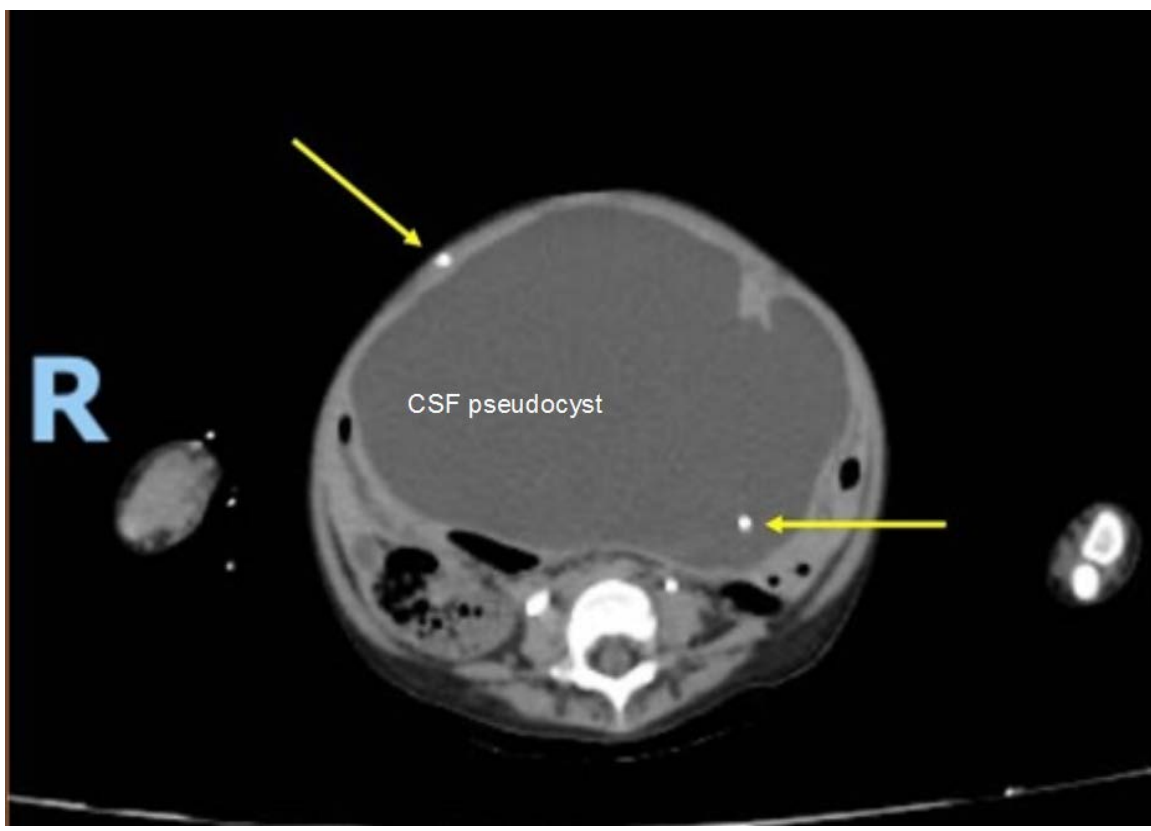

Figure 1. CT image showing the giant abdominal CSF pseudocyst. Arrows show the catheter on the left, still in the intramural pathway of the abdominal wall; and on the right, inside the large cyst. 
different amounts of CSF to other sites, such as the peritoneal cavity [6] or to the atrium (VPS) [14]. This type of treatment can present complications with an incidence of $5 \%$ to $47 \%$, which include infections, abscesses, intestinal perforation and abdominal pseudocysts [15], such as the present report. Signs of a malfunctioning in VPS are increased intracranial pressure (associated with headache, nausea, vomiting and altered level of consciousness), but hardly ever presents abdominal pain due to the accumulation of CSF in the peritoneal cavity [1] [9]. Over time, this accumulation of CSF can lead to a pseudocyst formation, which is a rare complication, with an incidence ranging from less than 1\% [16] to $10 \%$ [5] and a higher prevalence in children [9] and depend on a curious formation of the loops around a volume of CSF, forming a pseudocyst that consists of a fragile serous membrane due to a chronic inflammatory process, consisting of adhesions of the adjacent structures and organs (bowel loops) [2], with no epithelium [11].

Kashyap S. et al., 2017 [5], Tamura A. et al., 2013 [10], Pathi R. et al., 2004 [12], published clinical cases of abdominal CSF pseudocysts with larger volumes in children such as in the present report: the first one had $1.500 \mathrm{ml}$, the second $1.260 \mathrm{ml}$ and the third $2.100 \mathrm{ml}$, respectively [17].

There is no consensus about the best type of treatment for the CSF abdominal pseudocyst, and the decision should follow the symptoms presented by the patient [5] [9]. Paracentesis, CSF aspiration [10] [13], laparotomy or video-laparoscopic approach for debridement of adjacent structures can be performed [9] [18].

Percutaneous drainage with distal repositioning of the catheter in an alternative location (contralateral abdomen wall, pleural space or right atrium) or complete removal of the VPS from the third ventricle are the options for initial treatment of the condition [9] [10] [19]. In this report, the treatment of the pseudocyst was done through percutaneous drainage to decrease the large intra-abdominal volume.

In asymptomatic patients with small volume and those whose volume is not so large, the conduct can be non-operative. The prognosis is poor when taking into account the use of a new VPS, with recurrence rates varying from $7.1 \%$ to $62.5 \%[2]$.

\section{Conclusion}

In conclusion, this is a very low incidence case and the diagnostic can be strongly considered in children with a large abdominal distension with absence of intestinal involvement in patients with VPS.

\section{Conflicts of Interest}

The authors declare no conflicts of interest regarding the publication of this paper.

\section{References}

[1] Aquino, H.B.D. (2004) Complicações abdominais do cateter distal no tratamento da 
hidrocefalia com migração, perfuração e/ou extrusão: Uma hipótese inflamatória, dissertation, Faculdade de Ciências Médicas, Universidade Estadual de Campinas, Campinas.

[2] Chung, J.J., Yu, J.S., Kim, J.H., Nam, S.J. and Kim, M.-J. (2009) Intraabdominal Complications Secondary to Ventriculoperitoneal Shunts: CT Findings and Review of the Literature. American Journal of Roentgenology, 193, 1311-1317.

https://doi.org/10.2214/AJR.09.2463

[3] Sharifa, A.D. (2014) Ventriculoperitoneal Shunt with Communicating Peritoneal \& Subcutaneous Pseudocysts Formation. International Journal of Health Sciences, 8 , 107-111. https://doi.org/10.12816/0006076

[4] Figueiredo, D.G.D. and Carvalho, F.F.L.D. (1981) Pseudo-cistos peritoneais como complicação de derivações liquoricas: Relato de 3 casos e contribuição para o diagnóstico. Arquivos de Neuro-Psiquiatria, 39, 50-56.

https://doi.org/10.1590/S0004-282X1981000100006

[5] Kashyap, S., Ghanchi, H., Minasian, T., Dong, F. and Miulli, D. (2017) Abdominal Pseudocyst as a Complication of Ventriculoperitoneal Shunt Placement: Review of the Literature and a Proposed Algorithm for Treatment Using 4 Illustrative Cases. Surgical Neurology Internation, 8, Article No. 78.

https://doi.org/10.4103/2152-7806.206007

[6] Guest, B.J., Merjanian, M.H., Chiu, E.F. and Canders, C.P. (2019) Abdominal Cerebrospinal Fluid Pseudocyst Diagnosed with Point-of-Care Ultrasound. Clinical Practice and Cases in Emergency Medicine, 3, Article No. 43. https://doi.org/10.5811/cpcem.2018.11.40780

[7] Gaskill, S.J. and Marlin, A.E. (1989) Pseudocysts of the Abdomen Associated with Ventriculoperitoneal Shunts: A Report of Twelve Cases and a Review of the Literature. Pediatric Neurosurgery, 15, 23-27. https://doi.org/10.1159/000120436

[8] Karavdic, K., Karamustafic, A. and Herenda, N. (2019) Laparoscopic Management of Postventriculoperitoneal Shunt Abdominal Pseudocyst in 10 Years Old Girl. Surgeries, 1, Article No. 3. https://doi.org/10.35702/surg.10003

[9] Salomão, J.F. and Leibinger, R.D. (1999) Abdominal Pseudocysts Complicating CSF Shunting in Infants and Children. Pediatric Neurosurgery, 31, 274-278. https://doi.org/10.1159/000028875

[10] Tamura, A., Shida, D. and Tsutsumi, K. (2013) Abdominal Cerebrospinal Fluid Pseudocyst Occurring 21 Years after Ventriculoperitoneal Shunt Placement: A Case Report. BMC Surgery, 13, Article No. 27. https://doi.org/10.1186/1471-2482-13-27

[11] Burchianti, M. and Cantini R. (1988) Peritoneal Cerebrospinal Fluid Pseudocysts: A Complication of Ventriculoperitoneal Shunts. Child s Nervous System, 4, 286-290.

[12] Pathi, R., Sage, M., Slavotinek, J. and Hanieh, A. (2004) Abdominal Cerebrospinal Fluid Pseudocyst. Australasian Radiology, 48, 61-63.

https://doi.org/10.1111/j.1440-1673.2004.01245.x

[13] Anwar, R., Sadek, A.R. and Vajramani, G. (2017) Abdominal Pseudocyst: A Rare Complication of Ventriculoperitoneal Shunting. Practical Neurology, 17, 212-213. https://doi.org/10.1136/practneurol-2016-001579

[14] Clark, D.J., Chakraborty, A., Roebuck, D.J. and Thompson, D.N.P. (2016) Ultrasound Guided Placement of the Distal Catheter in Paediatric Ventriculoatrial Shunts-An Appraisal of Efficacy and Complications. Child's Nervous System, 32, 1219-1225. https://doi.org/10.1007/s00381-016-3120-4

[15] Hamid, R., Baba, A.A., Bhat, N.A., Mufti, G., Mir, Y.A. and Sajad, W. (2017) Post Ventriculoperitoneal Shunt Abdominal Pseudocyst: Challenges Posed in Manage- 
ment. Asian Journal of Neurosurgery, 12, 13-16.

[16] Leung, G.K.K. (2010) Abdominal Cerebrospinal Fluid (CSF) Pseudocyst Presented with Inferior Vena Caval Obstruction and Hydronephrosis. Child s Nervous System, 26, 1243-1245. https://doi.org/10.1007/s00381-010-1221-Z

[17] Koide, Y., Osako, T., Kameda, M., Ihoriya, H., Yamamoto, H., Fujisaki, N., et al. (2019) Huge Abdominal Cerebrospinal Fluid Pseudocyst Following Ventriculoperitoneal Shunt: A Case Report. Journal of Medical Case Reports, 13, Article No. 361. https://doi.org/10.1186/s13256-019-2308-0

[18] Sebastian, M., Sebastian, A., Sroczyński, M. and Rudnicki, J. (2018) Laparoscopic Management of Abdominal Pseudocyst Following Ventriculoperitoneal Shunt Implantation in Hydrocephalus. Videosurgery and Other Miniinvasive Techniques, 13, 260-265. https://doi.org/10.5114/wiitm.2018.72729

[19] Gmeiner, M., Wagner, H., van Ouwerkerk, W.J.R., Senker, W., Holl, K. and Gruber, A. (2018) Abdominal Pseudocysts and Peritoneal Catheter Revisions: Surgical Long-Term Results in Pediatric Hydrocephalus. World Neurosurgery, 111, e912-e920. https://doi.org/10.1016/j.wneu.2018.01.032 